\title{
Larger photovoltaic effect and hysteretic photocarrier dynamics in $\mathrm{Pb}\left[\left(\mathrm{Mg}_{1 / 3} \mathrm{Nb}_{2 / 3}\right)_{0.70} \mathrm{Ti}_{0.30}\right] \mathrm{O}_{3}$ crystal
}

\author{
A S Makhort, G Schmerber and B Kundys ${ }^{1}$ \\ Université de Strasbourg, CNRS, Institut de Physique et Chimie des Matériaux de Strasbourg, UMR 7504, 23 rue du Loess, F-67000 \\ Strasbourg, France
}

Keywords: ferroelectrics, photovoltaics, photopolarization

\begin{abstract}
Following the recent discovery of a bulk photovoltaic effect in the $\mathrm{Pb}\left[\left(\mathrm{Mg}_{1 / 3} \mathrm{Nb}_{2 / 3}\right)_{0.68} \mathrm{Ti}_{0.32}\right] \mathrm{O}_{3}$ crystal, we report here more than one order of magnitude improvement of photovoltaicity as well as its poling dependence in the related composition of lead magnesium niobate-lead titanate noted $\mathrm{Pb}\left[\left(\mathrm{Mg}_{1 / 3} \mathrm{Nb}_{2 / 3}\right)_{0.7} \mathrm{Ti}_{0.30}\right] \mathrm{O}_{3}$. Photocurrent measurements versus light intensity reveal a remarkable hysteresis in photocarrier dynamics clearly demonstrating charge generation, trapping and release processes.
\end{abstract}

\section{Introduction}

Ultimately approaching fundamental limit [1,2] of semiconductor photovoltaic (PV) technology stimulates the development of an alternative to $\mathrm{p}-\mathrm{n}$ junction-based solar energy conversion. One of the promising routes can be found in electrically polar materials where non-zero intrinsic electric field can replace p-n region of semiconducting photovoltaic cells with an ability to generate above bandgap photovoltages [3, 4]. Indeed, electrically polar photovoltaic materials have gain renewed attention in photovoltaics [5-11] and related multifunctionalities [12-21]. Although photovoltaic effect in non-centrosymetric crystals have long been known [22], renewed attention occurred after the discovery of photovoltaic effects in the multiferroic $\mathrm{BiFeO}_{3}[23,24]$ with recent progress in photovoltaic efficiency of $\mathrm{Bi}_{2} \mathrm{FeCrO}_{6}$ films, reporting a record value of $8.1 \%$ [25]. Because the bulk photovoltaic effect (BPVE) can be modified by extrinsic contributions (i.e. possible surface/interface effects in films [26] or grain size dependence in ceramics [27]) investigations on single crystals offer unique fundamental insight into photoelectric property. Among the still scarce PV compounds the initially nonphotovoltaic ferroelectric ( $\mathrm{FE}$ ) $\mathrm{Pb}\left[\left(\mathrm{Mg}_{1 / 3} \mathrm{Nb}_{2 / 3}\right)_{0.64} \mathrm{Ti}_{0.36}\right]_{3}$ ( $\mathrm{PMN}-\mathrm{PT} 36 \%$ ) crystals were reported to exhibit the PV effect after doping with $\mathrm{WO}_{3}$ [28]. Although this compound belongs to the well-known family of piezoelectric crystals with multifunctional phase diagram, other members of this composition were not tested until recently [29]. Since a much larger photovoltaic effect was found even in the undoped PMN-PT32\% crystal with a composition closer to the morphotropic phase boundary, a careful study of other compounds in the phase boundary region occurring between $\mathrm{PT}=30$ and $\mathrm{PT}=35 \%$ [30] becomes very promising. Here we report the existence of a photovoltaic effect in the PMN-PT30\% compound which exceeds by more than 1 order of magnitude the effect reported for the PMN-PT32\% counterpart. We further compare photovoltaic and ferroelectric performances of the two compositions and report unprecedented light-induced charge dynamics responsible for this effect.

\section{Experimental details}

The crystals had (001) orientation supplied by Crystal-Gmbh (Germany) in square shape with edges along [010] and [100] directions (figure 1(a) (inset)). Electrodes were formed with silver paste covering the edges in the planes parallel to $z y$. The hysteresis loop of polarization versus electric field was taken at room temperature by

\footnotetext{
${ }^{1}$ Author to whom any correspondence should be addressed (kundysATipcms.unistra.fr)
} 

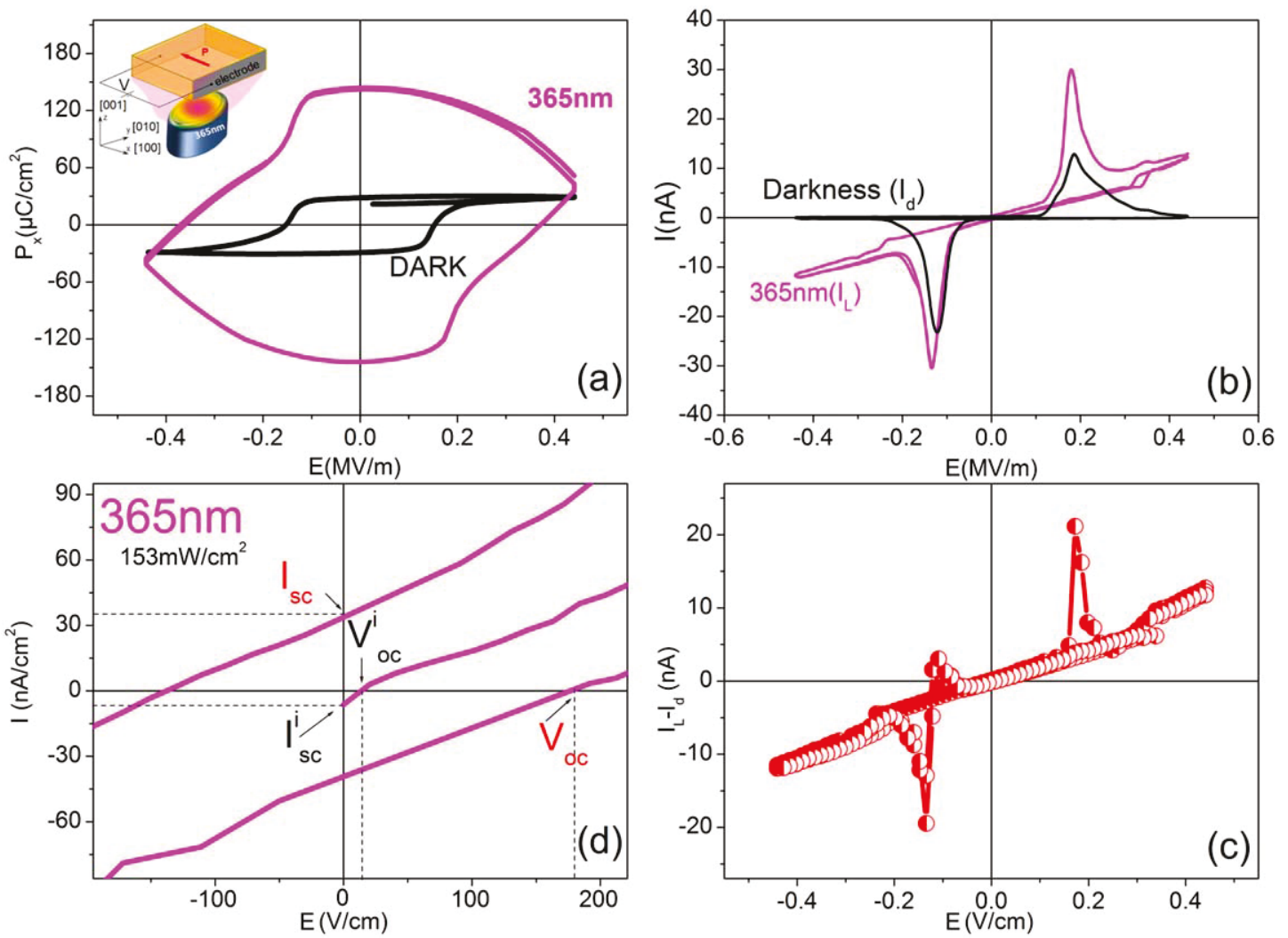

Figure 1. Ferroelectric polarization (a) and current loops (b) in darkness and under light ( $365 \mathrm{~nm}, 153 \mathrm{~mW} \mathrm{~cm}^{-2}$ ). Inset to figure 1 (a) shows schematics of the experiment. Figure (c) represents the difference between FE currents under light and in darkness. Figure (d) shows a zoomed evolution the ferroelectric current under light in the remanent polarization state with $\pm 1 \mathrm{kV} \mathrm{cm}^{-1} \mathrm{electric}_{\mathrm{c}}$ field amplitude.

using a quasi-static FE loop tracer similar to that described in [31], reducing FE fatigue by ultralow frequency $(0.01 \mathrm{~Hz})$ measurements. The sample was illuminated with a $365 \mathrm{~nm}(3.4 \mathrm{eV})$ UV-LED with $30 \mathrm{~nm}$ spectral linewidth with an intensity of $153 \mathrm{~mW} \mathrm{~cm}^{-2}$ in order to investigate the change in the FE polarization response. The current was monitored by a Keithley electrometer (Model 6517B) at the time constant of $0.36 \mathrm{~s}$. The temperature of the sample measured by a thermal camera (Therm-app) increases by $\leqslant 1.9 \mathrm{~K}$ under light illumination and such temperature change made no noticeable difference to the FE loop.

\section{Results and discussions}

The FE loop measured in darkness along [100] direction reveals a classical hysteresis behavior resulting in the two polarization states of about $\pm 29 \mu \mathrm{C} \mathrm{cm}^{-2}$, in agreement with the literature data (figure 1 (a)). However when illumination of $365 \mathrm{~nm}$ light is applied the apparent polarization increases by more than 4 times.

As a consequence of free charge generation by light, the sample becomes leakier FE with apparent increase in the both FE polarization and FE coercive force (figure 1(b)). The observed light-induced change in the ferroelectric loop largely exceeds in magnitude all previous observations [29, 32-34]. The corresponding voltampere characteristics further illustrate the photoinduced change in electric properties (figure 1(b)). The main three effects arise under light illumination: (i) the significant increase of current related to dipole reorientation (ferroelectric peak); (ii) the general increase in the sample conductivity; and (iii) a noticeable shift in abscissa of the FE loop as a result of light generated charges contribution to the total intrinsic electric field. The difference between FE currents in darkness and under illumination is presented in figure 1(c). As it can be seen the maximum of the light induced effect is achieved at the ferroelectric peak that is strongly poling history dependent in ferroelectrics. The change in the basic parameters of the photovoltaic effect is better illustrated in the zoomed region (figure $1(\mathrm{~d})$ ). The initial values of short circuit photocurrent $I_{s c}^{i}$ and open circuit photovoltage $V_{o c}^{i}$, increase largely after poling with $\pm 1 \mathrm{kV} \mathrm{cm}^{-1}$. In particular, there is also a noticeable down shift of the loop along $y$-axis, so the absolute the value of $I_{s c}$ after pooling with $+1 \mathrm{kV} \mathrm{cm}^{-1}$ is smaller than the value of $I_{s c}$ obtained after pooling with $-1 \mathrm{kV} \mathrm{cm}^{-1}$. Same effect is also seen for open circuit photovoltage $V_{o c}$. Because $I_{s c}$ and $V_{o c}$ are used to evaluate photovoltaic efficiency, the electric tuning becomes possible. These 


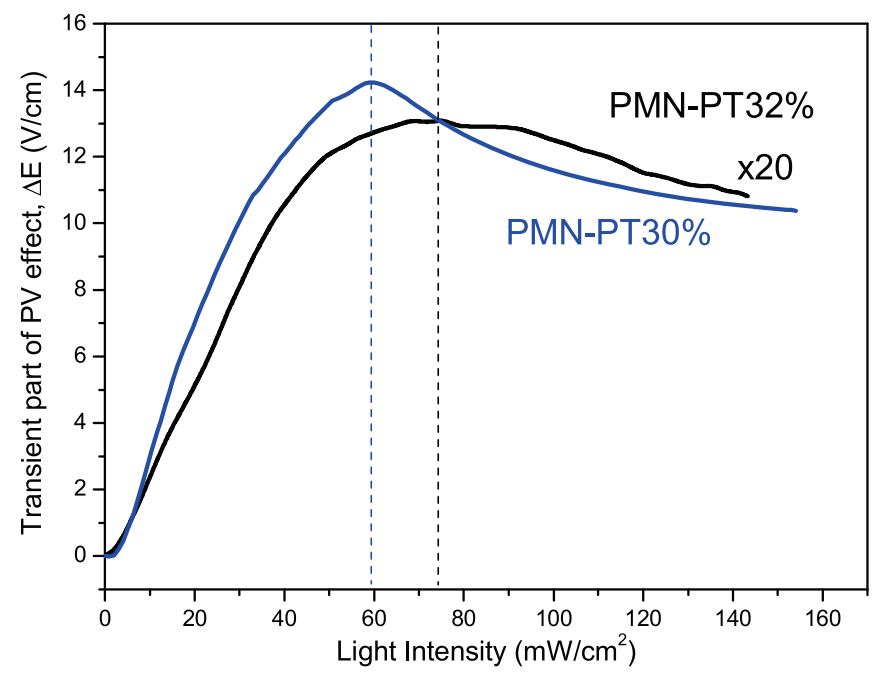

Figure 2. Comparison of photovoltaic effect for the $\mathrm{Pb}\left[\left(\mathrm{Mg}_{1 / 3} \mathrm{Nb}_{2 / 3}\right)_{0.68} \mathrm{Ti}_{0.32}\right] \mathrm{O}_{3}(32 \%)$ and $\mathrm{Pb}\left[\left(\mathrm{Mg}_{1 / 3} \mathrm{Nb}_{2 / 3}\right)_{0.70} \mathrm{Ti}_{0.30}\right] \mathrm{O}_{3}(30 \%)$ crystals at room temperature for samples in a remanent $\mathrm{FE}$ state.

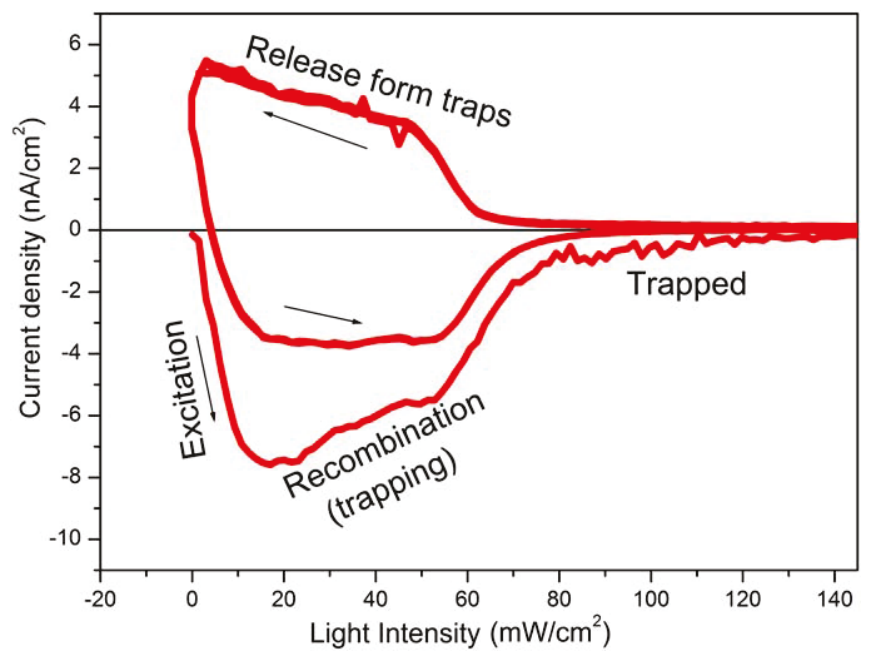

Figure 3. Photocurrent as a function of light intensity for $\mathrm{Pb}\left[\left(\mathrm{Mg}_{1 / 3} \mathrm{Nb}_{2 / 3}\right)_{0.70} \mathrm{Ti}_{0.30}\right] \mathrm{O}_{3}(30 \%)$ crystals at room temperature.

extraordinary properties were more clearly observed by us in the photovoltaic $\mathrm{Bi}_{2} \mathrm{FeCrO}_{6}$ films [35] and can be expected to be a general and technologically important electrically switchable feature for photovoltaic ferroelectric compounds.

At ferroelectric remanence the voltage change versus light intensity shows a $\sim 20$-times larger effect than in the PMN-PT32\% crystal (figure 2) in agreement with much larger effect of the light on the FE loop (figure 1(a) and [29]). The nonlinear behavior as a function of light intensity with a characteristic peak is observed for both compounds. The form of curves can be explained by the occurrence of two competing mechanisms: the light induced charge generation dominant at low light intensities and the charge recombination processes at higher intensities (figure 2). These opposing processes give rise to the peak as a function of light intensity at the value where numbers of generated and recombined carriers are expected to become comparable. Notably, the maximum photovoltaic effect is reached faster for the PMN-PT30\% $\left(\sim 59 \mathrm{~mW} \mathrm{~cm}^{-2}\right)$ than for PMN-PT32\% $\left(74 \mathrm{~mW} \mathrm{~cm}^{-2}\right)$. In order to get insight into the origin of the observed behavior we have measured the related electric current as a function light intensity (so-called Lux-Ampere-like characteristic (figure 3)). Prior to measurements the sample was set to the remanent polarization state by sweeping the electric field from $-0.4 \mathrm{MV} \mathrm{m}^{-1}$ to $+0.4 \mathrm{MV} \mathrm{m}^{-1}$ and then to zero, to ensure a monodomain configuration. The light intensity was then increased and the current was monitored by a Keithley electrometer (Model 6517B) with a related time constant of $0.36 \mathrm{~s}$. The observed behavior can be tentatively explained as follows. The charges, initially generated by light, move in the previously defined polarization direction, and therefore create a current (linear part, 


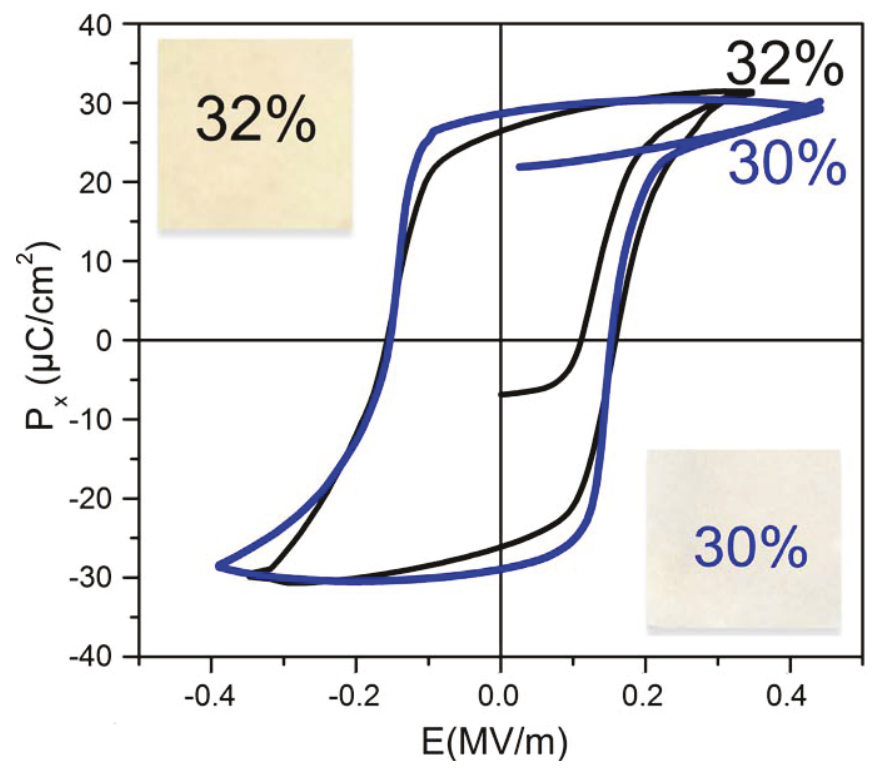

Figure 4. Comparison of ferroelectric loops in darkness between $\mathrm{Pb}\left[\left(\mathrm{Mg}_{1 / 3} \mathrm{Nb}_{2 / 3}\right)_{0.68} \mathrm{Ti}_{0.32}\right] \mathrm{O}_{3}(32 \%)$ and $\mathrm{Pb}\left[\left(\mathrm{Mg}_{1 / 3} \mathrm{Nb}_{2 / 3}\right)_{0.70} \mathrm{Ti}_{0.30}\right] \mathrm{O}_{3}(30 \%)$ crystals. Insets shows pictures of the both crystals on white background indicating larger absorption in the case of $\mathrm{Pb}\left[\left(\mathrm{Mg}_{1 / 3} \mathrm{Nb}_{2 / 3}\right)_{0.68} \mathrm{Ti}_{0.32}\right] \mathrm{O}_{3}(32 \%)$ (yellow color).

figure 3). This light-induced charge generation process eventually reaches its saturation and the photo-carriers start to recombine reducing the related current to zero (trapped state, figure 3 ).

As light intensity decreases, this process is reversed, and the majority of carriers become free again, but now move in the opposite direction, in agreement with the sign change of the photocurrent (see 'release from traps' part in figure 3). Subsequent illumination reveals a smaller magnitude of the photocurrent, because a part of photo-excited carriers had recombined irreversibly, diminishing surface charges, and therefore decreasing polarization [29]. The role of polarization magnitude in the PV effect can be verified by comparing ferroelectric loops of both compounds in darkness (figure 4). The PMN-PT30\% compound with a larger photovoltaic effect indeed shows a slightly larger remanent polarization.

However, the difference of $0.2 \mu \mathrm{C} \mathrm{cm}^{-2}$ is rather too small to be responsible for the large difference in the photovoltaic properties reported in figure 2 . The same argument can be pointed out for pyroelectric coefficients that do not change much for $\mathrm{Pb}\left[\left(\mathrm{Mg}_{1 / 3} \mathrm{Nb}_{2 / 3}\right)_{x} \mathrm{Ti}_{1-x}\right] \mathrm{O}_{3}$ composition for $0.3<x<0.32$ [36]. Another explanation can be based on the possible difference in the optical absorption coefficients between the two compounds. However, the optical absorption is known to decrease with decreasing $x$ in the $\mathrm{Pb}\left[\left(\mathrm{Mg}_{1 / 3} \mathrm{Nb}_{2 / 3}\right)_{x} \mathrm{Ti}_{1-x}\right] \mathrm{O}_{3}$ composition [37] in agreement with the fact that the $\mathrm{Pb}\left[\left(\mathrm{Mg}_{1 / 3} \mathrm{Nb}_{2 / 3}\right)_{0.70} \mathrm{Ti}_{0.30}\right] \mathrm{O}_{3}$ (PT30\%) crystals are more transparent at ambient conditions (figure 4 (insets)). On the other hand, the composition of $\mathrm{Pb}\left[\left(\mathrm{Mg}_{1 / 3} \mathrm{Nb}_{2 / 3}\right)_{x} \mathrm{Ti}_{1-x}\right] \mathrm{O}_{3}$ crystals is optimized to obtain large piezoelectric properties, reaching a maximum for $x=0.3$, exactly at the lower morphotropic phase boundary [30]. Thus, thanks to the enhanced piezoelectric properties in the PMN-PT30\% compound, the light-generated charges can contribute more efficiently to the electric field-assisted transformation between the thermodynamically equivalent phases at the morphotropic phase boundary. The light then induces changes in polarization that are connected to stress. Consequently, the larger is the piezoelectric coefficient, the larger light-induced effect is expected on the lattice deformation [38], which, in turn can modify the bandgap [39-41] of the material leading to the increased photovoltaic effect. Although this mechanism is possible, its contribution is unlikely dominant here because the piezoelectric coefficients do not differ by the order of magnitude in both compounds [30]. The intrinsic mechanism of light induced charge generation may come into play deserving a separate study including symmetry dependent [29] and defect dependent [42] arguments.

\section{Conclusions}

In conclusion, an enhancement in the photovoltaic effect of more than one order of magnitude has been found in the $\mathrm{Pb}\left[\left(\mathrm{Mg}_{1 / 3} \mathrm{Nb}_{2 / 3}\right)_{0.70} \mathrm{Ti}_{0.30}\right]_{3}$ compound, with the composition at the lower border of the morphotropic phase diagram. The much larger photovoltaic effect at the lower border of the MPB and unprecedented LuxAmpere-like characteristic demonstrating hysteretic photo carrier dymamics for the first time should be regarded as key basic findings. This study should rapidly prompt a screen of other compounds of the same family 
as well as similar compositions [43-45] in which photovoltaic effects can occur thanks to acentricity [46] with the aim to better understand and optimize their photovoltaic properties.

\section{References}

[1] Shockley W and Queisser H J 1961 Detailed balance limit of efficiency of p-n junction solar cells J. Appl. Phys. 32 510-9

[2] Huang J, Yuan Y, Shao Y and Yan Y 2017 Understanding the physical properties of hybrid perovskites for photovoltaic applications Nat. Rev. Mater. 217042

[3] Pérez-Tomás A, Lira-Cantú M and Catalan G 2016 Above-Bandgap Photovoltages in Antiferroelectrics Adv. Mater. 28 9644-7

[4] Yang S Y et al 2010 Above-bandgap voltages from ferroelectric photovoltaic devices Nat. Nanotechnol. 5 143-7

[5] Butler K T, Frost J M and Walsh A 2015 Ferroelectric materials for solar energy conversion: photoferroics revisited Energy Environ. Sci. 8 $838-48$

[6] Paillard C, Bai X, Infante I C, Guennou M, Geneste G, Alexe M, Kreisel J and Dkhil B 2016 Photovoltaics with ferroelectrics: current status and beyond Adv. Mater. $285153-68$

[7] Grinberg I et al 2013 Perovskite oxides for visible-light-absorbing ferroelectric and photovoltaic materials Nature 503 509-12

[8] Lopez-Varo P et al 2016 Physical aspects of ferroelectric semiconductors for photovoltaic solar energy conversion Phys. Rep. 653 1-40

[9] Matsuo H, Noguchi Y and Miyayama M 2017 Gap-state engineering of visible-light-active ferroelectrics for photovoltaic applications Nat. Commun. 8207

[10] Spanier J E et al 2016 Power conversion efficiency exceeding the Shockley-Queisser limit in a ferroelectric insulator Nat. Photonics 10 611-6

[11] Inoue R, Ishikawa S, Imura R, Kitanaka Y, Oguchi T, Noguchi Y and Miyayama M 2015 Giant photovoltaic effect of ferroelectric domain walls in perovskite single crystals Sci. Rep. 514741

[12] Kundys B, Viret M, Colson D and Kundys D O 2010 Light-induced size changes in $\mathrm{BiFeO}_{3}$ crystals Nat. Mater. 9803

[13] Kreisel J, Alexe M and Thomas P A 2012 A photoferroelectric material is more than the sum of its parts Nat. Mater. $11260-260$

[14] Mettout B and Gisse P 2017 Theory of the photovoltaic and photo-magneto-electric effects in multiferroic materials Ferroelectrics 506 93-110

[15] Rubio-Marcos F, Ochoa D A, Campo A D, García M A, Castro G R, Fernández J F and García J E 2018 Reversible optical control of macroscopic polarization in ferroelectrics Nat. Photonics 1229

[16] Dejneka A and Tyunina M 2018 Elasto-optic behaviour in epitaxial films of perovskite oxide ferroelectrics Adv. Appl. Ceram. 117 62-5

[17] Iurchuk V et al 2016 Optical writing of magnetic properties by remanent photostriction Phys. Rev. Lett. 117107403

[18] Manz S, Matsubara M, Lottermoser T, Büchi J, Iyama A, Kimura T, Meier D and Fiebig M 2016 Reversible optical switching of antiferromagnetism in $\mathrm{TbMnO}_{3}$ Nat. Photonics 10653

[19] Páez-Margarit D, Rubio-Marcos F, Ochoa D A, Del Campo A, Fernández J F and García J E 2018 Light-Induced capacitance tunability in ferroelectric crystals ACS Appl. Mater. Interfaces $1021804-7$

[20] Bai Y, Vats G, Seidel J, Jantunen H and Juuti J 2018 Boosting photovoltaic output of ferroelectric ceramics by optoelectric control of domains Adv. Mater. 301803821

[21] Li Y, Cui X, Sun N, Du J, Li X, Jia G and Hao X 2018 Region-Dependent and stable ferroelectric photovoltaic effect driven by novel inplane self-polarization in narrow-bandgap $\mathrm{Bi}_{2} \mathrm{FeMo}_{0.7} \mathrm{Ni}_{0.3} \mathrm{O}_{6}$ thin film Adv. Opt. Mater. 01801105

[22] Fridkin V 1979 Photoferroelectrics (Berlin: Springer-Verlag)

[23] Choi T, Lee S, Choi Y J, Kiryukhin V and Cheong S-W 2009 Switchable Ferroelectric diode and photovoltaic effect in BiFeO 3 Science 32463-6

[24] Yi H T, Choi T, Choi S G, Oh Y S and Cheong S-W 2011 Mechanism of the switchable photovoltaic effect in ferroelectric BiFeO 3 Adv. Mater. 23 3403-7

[25] Nechache R, Harnagea C, Li S, Cardenas L, Huang W, Chakrabartty J and Rosei F 2015 Bandgap tuning of multiferroic oxide solar cells Nat. Photonics $961-7$

[26] Calzada M L, Jiménez R, González A, García-López J, Leinen D and Rodríguez-Castellón E 2005 Interfacial phases and electrical characteristics of ferreoelectric strontium bismuth tantalate films on $\mathrm{Pt} / \mathrm{TiO}_{2}$ and $\mathrm{Ti} / \mathrm{Pt} / \mathrm{Ti}$ heterostructure electrodes Chem. Mater. 17 $1441-9$

[27] Takagi K, Kikuchi S, Li J-F, Okamura H, Watanabe R and Kawasaki A 2004 Ferroelectric and photostrictive properties of fine-grained PLZT ceramics derived from mechanical alloying J. Am. Ceram. Soc. 87 1477-82

[28] Tu C-S, Wang F-T, Chien R R, Schmidt V H, Hung C-M and Tseng C-T 2006 Dielectric and photovoltaic phenomena in tungstendoped $\mathrm{Pb}\left(\mathrm{Mg}_{1 / 3} \mathrm{Nb}_{2 / 3}\right)_{1-\mathrm{x}} \mathrm{Ti}_{\mathrm{x}} \mathrm{O}_{3}$ crystal Appl. Phys. Lett. 88032902

[29] Makhort A S, Chevrier F, Kundys D, Doudin B and Kundys B 2018 Photovoltaic effect and photopolarization in $\mathrm{Pb}\left[\left(\mathrm{Mg}_{1 / 3} \mathrm{Nb}_{2 / 3}\right)_{0.68} \mathrm{Ti}_{0.32}\right] \mathrm{O}_{3}$ crystal Phys. Rev. Mater. 2012401

[30] Guo Y, Luo H, Ling D, Xu H, He T and Yin Z 2003 The phase transition sequence and the location of the morphotropic phase boundary region in $(1-\mathrm{x})\left[\mathrm{Pb}\left(\mathrm{Mg}_{1 / 3} \mathrm{Nb}_{2 / 3}\right) \mathrm{O}_{3}\right]-\mathrm{xPbTiO}_{3}$ single crystal J. Phys. Condens. Matter $15 \mathrm{~L} 77$

[31] Mastner J 1968 A quasistatic hysteresis loop tracer J. Phys. [E] 11249

[32] Kholkin A L, Iakovlev S O and Baptista J L 2001 Direct effect of illumination on ferroelectric properties of lead zirconate titanate thin films Appl. Phys. Lett. 79 2055-7

[33] Borkar H, Tomar M, Gupta V, Katiyar R S, Scott J F and Kumar A 2017 Optically controlled polarization in highly oriented ferroelectric thin films Mater. Res. Express 4086402 
[34] Borkar H, Rao V, Tomar M, Gupta V, Scott J F and Kumar A 2017 Experimental evidence of electronic polarization in a family of photo-ferroelectrics RSCAdv. 7 12842-55

[35] Quattropani A et al 2018 Tuning photovoltaic response in $\mathrm{Bi}_{2} \mathrm{FeCrO}_{6}$ films by ferroelectric poling Nanoscale 10 13761-6

[36] Tang $\mathrm{Y}$ and Luo $\mathrm{H} 2009$ Investigation of the electrical properties of $(1-\mathrm{x}) \mathrm{Pb}\left(\mathrm{Mg}_{1 / 3} \mathrm{Nb}_{2 / 3}\right) \mathrm{O}_{3}-\mathrm{x} \mathrm{PbTiO}_{3}$ single crystals with special reference to pyroelectric detection J. Phys. Appl. Phys. 42075406

[37] Chan K Y, Tsang W S, Mak C L, Wong K H and Hui P M 2004 Effects of composition of $\mathrm{PbTiO}_{3}$ on optical properties of $(1-\mathrm{x}) \mathrm{PbMg}_{1 / 3} \mathrm{Nb}_{2 / 3} \mathrm{O}_{3}-\mathrm{xPbTiO}_{3}$ thin films Phys. Rev. B 69144111

[38] Kundys B 2015 Photostrictive materials Appl. Phys. Rev. 2011301

[39] Dejneka A, Chvostova D, Pacherova O, Kocourek T, Jelinek M and Tyunina M 2018 Optical effects induced by epitaxial tension in lead titanate Appl. Phys. Lett. 11203111

[40] Rai D P, Kaur S and Srivastava S 2018 Band gap modulation of mono and bi-layer hexagonal ZnS under transverse electric field and biaxial strain: a first principles study Phys. B Condens. Matter $53190-4$

[41] Pasynkov R E 1973 On some problems of the phenomenological theory of ferroelectric-semiconductors Ferroelectrics 6 19-27

[42] Bai Z, Geng W, Zhang Y, Xu S, Guo H and Jiang A 2017 The abnormal photovoltaic effect in BiFeO $_{3}$ thin films modulated by bipolar domain orientations and oxygen-vacancy migration Appl. Phys. A 123561

[43] Wu F, He X, Zhang J, Yang B, Sun E, Jiang J and Cao W 2016 Optical bandgap and dispersions of $0.24 \mathrm{~Pb}\left(\mathrm{In}_{1 / 2} \mathrm{Nb}_{1 / 2}\right) \mathrm{O}_{3}-0.43 \mathrm{~Pb}\left(\mathrm{Mg}_{1 / 3} \mathrm{Nb}_{2 / 3}\right) \mathrm{O}_{3}-0.33 \mathrm{PbTiO}_{3}$ single crystal poled along [011]c direction Opt. Mater. 60 101-4

[44] He C, Chen Z, Chen H, Wu T, Wang J, Gu X, Liu Y and Zhu K 2018 Anisotropy electric and optical properties of PIMNT single crystal J. Nanophotonics 12046019

[45] Li Y, Tang Y, Wang F, Zhao X, Chen J, Zeng Z, Yang L and Luo H 2018 Optical properties of Mn-doped $0.15 \mathrm{~Pb}\left(\mathrm{In}_{1 / 2} \mathrm{Nb}_{1 / 2}\right) \mathrm{O}_{3}-$ $0.57 \mathrm{~Pb}\left(\mathrm{Mg}_{1 / 3} \mathrm{Nb}_{2 / 3}\right) \mathrm{O}_{3}-0.28 \mathrm{PbTiO}_{3}$ single crystal Appl. Phys. A 124276

[46] von Baltz R and Kraut W 1981 Theory of the bulk photovoltaic effect in pure crystals Phys. Rev. B 23 5590-6 